\title{
HACIA UN REENCANTAMIENTO VIRTUAL DEL MUNDO SOCIAL: CONSECUENCIAS DE LA TECNOLOGÍA EN LA JUVENTUD'
}

\author{
Jerjes Loayza
}

\section{RESUMEN}

La tecnología va acrecentando su impacto en la socialización, siendo las juventudes sus principales consumidores tecnológicos. En este contexto asistimos no solo a un reencantamiento del mundo que va sumergiéndose en la magia de la simultaneidad de virtualidad, sino en la re oralización de la mente y de la interacción social. A su vez, tomando el celular como ejemplo, dichas tecnologías van ensamblándose al cuerpo humano, volviéndose una parte más de la extensión del cuerpo humano. A modo de reflexión crítica, se sostiene que dicha situación no es analizada ni sopesada en sus consecuencias más directas, tanto en su nivel psíquico, social y material. Se cree que dichas tecnologías estarían oralizando la reflexión y aislando al sujeto en un estar-juntos, cada vez más contradictoriamente alejado de su sociedad.

PALABRAS CLAVE: Juventud, oralidad, reencantamiento, ensamblaje.

\section{TOWARDS A VIRTUAL WORLD SOCIAL REENCHANTMENT: CONSEQUENCES TECHNOLOGY IN YOUTH}

\begin{abstract}
Technology is increasing its impact on socialization, being its main technological youths consumers. In this context we are witnessing not only a re-enchantment of the world that is plunging into the magic of the simultaneity of virtuality, but in the re oralization of mind and social interaction. In turn, taking as an example cell, such technologies are being assembled to the human body, becoming a part of the extension of the human body. A critical reflection mode, it is argued that this situation is not analyzed and weighed in its most direct, both in psychological, social and material level consequences. It is believed that such technologies would oral way reflection and isolating the subject in a living- together, increasingly contradictory away from their society.
\end{abstract}

KEYWORDS: Youth, orality, enchantment, assembly.

1 Investigación realizada durante el año 2014 con el auspicio de la Universidad Ricardo Palma. 


\section{Introducción}

S e viven nuevos tiempos que han generado tecnologías que invaden cada pequeño espacio de nuestra cotidianidad, o más precisamente se viven nuevos tiempos gracias a aquellas tecnologías que hemos de concebir como mediadores que han sido capaces de transformarnos psíquica, material y socialmente. Sin embargo el complejo impacto que la técnica demuestra hoy, ha venido dándose desde hace muchos años, siendo una constante histórica: el invento de Gutemberg, la imprenta, nos llevó a concebir el mundo desde la lectura, desde los libros, desde los ojos y la reflexión. Si bien la escritura ya se había descubierto, no fue sino con la masiva reproducción de textos escritos que el modo de ver el mundo cambiaría para siempre. La oralidad sería relegada poco a poco para las muchedumbres analfabetas europeas en donde las desigualdades sociales empezaron a tener la educación como un modo de clasificar a las personas, ya que ésta se reservaba para los grupos pudientes. Poco a poco la oralidad fue reservándose a cuestiones cotidianas, sin importancia, relevándose el rol de la escritura.

Sin embargo, con el avance de la técnica, acaeció sobre la humanidad un supuesto atraso: la radio y la televisión nos introdujeron de vuelta al mundo de la oralidad, del oído, de las frases entrecortadas, de la superficialidad comunicativa. Eran tiempos en que los inventos eléctricos asombraban a todos. Para muchos pensadores regresábamos a un mundo más confiable y menos frío como el de la escritura, para otros era un retorno a la barbarie. El debate no sería capaz de influenciar en lo que vendría cincuenta años después. La técnica se abrió paso entre la vida de las personas y generó verdaderas revoluciones de la comunicación a través del internet y la comunicación celular. Hoy el debate es más agudo que nunca, pero sus consumidores poco o nada quieren saber al respecto, siempre que tengan batería suficiente para continuar sus vidas de la mano con aquellos apéndices orgánicos. Sin embargo ¿estamos más unidos que nunca gracias a una nueva oralidad (que llamaremos electronalidad) que ha conquistado el planeta? ¿Aquella aldea global que algún día postularía Mc Luhan se hizo posible? ¿No será que navegamos por redes sociales que nos alejan de una noción colectiva de las cosas? ¿Las creaciones han terminado por rebasar a sus hacedores, como diría Latour?

Sin embargo, aunque los posmodernistas propondrían que acudiríamos al reencantamiento del mundo, puesto que si bien, a decir de Weber (Arriaga, 2012) la racionalización ha venido desencantando el mundo, la tecnología ha sido capaz de reencatarlo. Maffesoli lo establece así:

La técnica desencantaba. Ahora nos encontramos con que los teléfonos celulares, las computadoras, el equipo eléctrico o electro-cibernético reencantan. Las imágenes y la música que nos llega vía estos equipos técnicos nos ofrecen un claro testimonio de ello. Tenemos, entonces, que la técnica reencanta, es decir, le da una fuerza y un vigor indiscutible a estos nuevos medios mágicos, si se pudiera decir así (Cit. en Arriaga, 2012: 222). 
Para este autor, la racionalización aísla a los individuos. En efecto, ello podemos analizarlo a la luz de la escribalidad. Ahora bien, según refiere, es la técnica la que, hoy en día, es capaz de relacionar a dichos individuos aislados. En base a dicho debate analizaremos en este texto el modo en que las tecnologías vienen transformando la socialización juvenil, y el impacto que ello tiene en su vida psíquica, social y material. Partimos de que, tal como sostiene Rorty (1991), para referirse a lo sostenido por Derrida, nada habla jamás "por sí mismo", porque nada tiene la primordialidad -el carácter no relacional, absoluto- que el metafísico busca.

\section{Las resignificaciones sociales de la tecnología}

Los medios de comunicación vienen siendo base fundamental de una sociedad que aparentemente pareciera aceptar sin límites todo cuanto la televisión dice. Para Sartori (1998) no se cuestionan los contenidos televisivos, ignorando el modo en que los gobiernos han utilizado los medios de comunicación para manipular a las masas: la información presentada por los medios se encuentra descontextualizada, manipulada y generada en base a unos intereses propios. Pero en esta ocasión no nos detendremos en los contenidos, que de por sí inquietan a toda una generación (la generación $Z$ como le llamaron a aquella nacida a mediados de los 90), sino en las consecuencias psíquicas y mentales que vienen operando sobre cada uno de nosotros, sus confiados e inocentes consumidores que derrochamos energía en la utilización de los mismos, ante la inquebrantable idea de cuánto nos facilitan la vida, viviendo el mejor de los tiempos posibles: hemos superado la calidad de vida de nuestros padres gracias a la tecnología que rodea nuestra cotidianidad.

Para reflexionar sobre la magnitud de las consecuencias de los medios de comunicación en estos aspectos, podemos ensayar la comparación entre una computadora que funcione correctamente como un caso de intermediario, y una conversación banal a través de aquella computadora. Esta última es capaz de convertirse en una cadena compleja de mediadores donde se bifurcan a cada paso pasiones, las opiniones y las actitudes (Latour, 2008: 63), es decir la propia máquina desdibuja nuestros mensajes, los transforman y los adecúan insertándose en una comunicación que antes se limitaba a dos personas: los mediadores intervienen en el contenido de nuestros mensajes. Se viven nuevos tiempos que si bien surgen de nuevos enfoques, estos relativizan nuestros esfuerzos en la medida que nos afecta directamente obnubilando cualquier juicio crítico:

Hoy, en la era electrónica de la simultaneidad, ha sido necesario invertir los términos comenzando por una nueva tendencia hacia la descentralización y el pluralismo (...) esta es la razón de que ahora resulte tan fácil comprender la lógica dinámica de la imprenta como una fuerza centralizadora y homogeneizante. Porque todos los efectos de la tec- 
nología de la imprenta están ahora en enérgica oposición a la tecnología electrónica (McLuhan, 1985:272).

Aquel profeta dijo aquello hace cincuenta años, y si algo podemos aprender de ello es la urgente acción de invertir las categorías aceptando el pluralismo como un aliado, antes que como un enemigo. Nuestra tecnología electrónica está tan inserta en nuestros tiempos que se hace un verdadero reto hablar de ella sin dejar de pensar desde una perspectiva sugestionada, menos aun cuando quien escribe estas líneas se ha socializado a la luz de aquella tecnología del internet que hoy se atreve a analizar: busqué mucha información diversa en la web, platiqué e intercambié información con amigos y amigas mediante el chat, estuve siempre atento al celular para coordinaciones diversas, etc. Aunque, a su vez, no es negativo, pues para proponer una metafísica alternativa el científico social primero debe involucrarse en las actividades con las que hacen aquellas personas a quienes está estudiando (Latour, 2008: 87).

Propongo sostener un diálogo entre el análisis histórico del pasado y de lo que viene aconteciendo, me refiero a una re-interpretación, re-creación y re-composición de cuanto hemos heredado, con añadiduras que puedan no sólo renovar las teorías, sino transformarlas en nuevos enfoques, ya que nuestra época nos insta a cruzar barreras, borrar antiguas categorías y explorar de todas las formas concebidas (McLuhan, 1983). Quién sino un artista de las letras lo puede expresar mejor: "Yo recojo las enseñanzas de los viejos y creo en los límites de lo que va desapareciendo. Vanguardia y retaguardia no tienen para mí ningún sentido: lo importante es ser fiel a mis impulsos y transmitir, simplemente, el rumor de la vida" (Ribeyro, 1986:7). El análisis de los acontecimientos del pasado, nos permitirá la comprensión de un presente en cuyo seno sobrevive una historia tan viva como recurrente: el estudio de la tecnología requiere una entrada necesariamente historizante.

Comprendamos el devenir histórico: si la tecnología eléctrica hace más de 50 años promovía y estimulaba el envolvimiento, lo que hoy provocan los mediadores electrónicos es aún más colosal: es imposible comprender los cambios sociales y culturales si no se conoce el funcionamiento de los medios (Mc Luhan, 1983). Para Benjamin (2003:114) si bien la vida de las masas ha sido decisiva siempre para el rostro de la historia, habría percibido ya por la década de 1930 cómo las masas expresaban de manera consciente, y como si fueran los músculos de ese rostro, una mímica del mismo, un fenómeno completamente nuevo que es capaz de hacerse patente de muchas maneras. Si bien es cierto su análisis presenta referencias "no - lógicas", considerados desde una perspectiva purista como meros barbarismos, el que sea imposible suprimirlas en la vida cotidiana debido a su uso constante, nos anima preciosamente aún más a su investigación (Maffesoli 1993). Sin embargo el reto no es sencillo, más aun partiendo de sus propios usos y estilos que resultan tan contradictorios a partir de fenómenos como la comunicación mal escrita, los iconos incomprensibles, la exposición pública de lo privado, las ironías racistas y patriarcales, entre otros fenómenos. 
La arremetida tecnológica es capaz de resignificar los discursos y las prácticas sociales, siendo de capital importancia para las ciencias sociales un análisis de tipo transversal. Ello se refuerza si hablamos de consumidores que han hecho de este contexto virtual la principal base de su socialización. Lo más preocupante no tendrá que ver con la socialización en cuanto a formas, sino a contenidos (Ángeles, 2010), una lógica del debe ser que es arremetida por una realidad cada vez más rebelde e incierta. La curiosidad y el conocimiento sin límites es uno de los motores de su acceso a la red. Para algunos, las comunidades en el ciberespacio surgen en parte debido a la desaparición de espacios públicos informales en la vida real (Huber, 2002). Pareciera, más bien, que los espacios públicos informales han pasado a ser también espacios virtuales. Más aun, lo real y lo virtual funciona a modo de complemento, reforzándose y retroalimentándose.

\section{El impacto de los mediadores electrónicos en la comunicación social}

Si bien las nuevas tecnologías de información cada vez tienen un rol más importante no sólo en los procesos de aprendizaje sino en la socialización de pares diversos y no solamente juveniles ¿Por qué los artefactos que nos insertan al mundo virtual son considerados como importantes en la práctica social? En lugar de respuestas, la gama de preguntas se vuelve aún más impertinente: ¿cómo es que un simple chat puede recrear el trasfondo de nuestros discursos? ¿Cómo es que el uso o abuso de las redes sociales nos puede llevar a experimentar una socialización tan distante a la vivida por nuestros padres? Para ser más exactos ¿cómo es que estos mediadores son capaces de cambiarnos a nosotros mismos si el mensajero no debería tener mayor relevancia? Mc Luhan pudo encontrar la respuesta a estas preguntas, ya que se dio cuenta de cómo es que nuestros sentidos corporales funcionaban como sistemas capaces de traducirse unos a otros en la experiencia de la conciencia. Aquel autor plantearía el modo en que las prolongaciones de nuestros sentidos habían sido, en el transcurso del tiempo, sistemas cerrados incapaces de interacción o conciencia colectiva. Llegaría a esta conclusión a través del análisis de la era eléctrica que se vivió durante la primera mitad del siglo veinte:

Hoy, en la era eléctrica, el propio carácter instantáneo de la coexistencia entre nuestros instrumentos tecnológicos ha originado una crisis sin precedentes en la historia de la humanidad. Esas extensiones de nuestras facultades y sentidos constituyen ahora un particular campo de experiencia que reclama que aquellos se hagan patentes a una conciencia colectiva (MacLuhan, 1985: 12).

Los mediadores se transformarían en el verdadero mensaje, ya que aquellos soportes que considerábamos como inertes e insignificantes de por sí, terminarían por re crear el sentido de lo social. Para dilucidar este punto, hemos de distinguir entre lo que nos 
puede resultar un intermediario que puede interesarle a un ingeniero de sistemas, un técnico o algún interesado en cuestiones electrónicas. Para Latour (2008) el intermediario transporta significado o fuerza sin transformación: definir sus datos de entrada basta para definir sus datos de salida. Éste funciona como unidad aunque lo compongan muchas partes. Las ciencias sociales tendrían interés en estos artefactos toda vez se transformen en mediadores. Éstos, a diferencia de los intermediarios, no pueden considerarse solo uno, pueden funcionar como uno, nada, varios o infinito. A decir de Latour, sus datos de entrada nunca predicen bien los de salida; su especificidad debe tomarse en cuenta cada vez. De este modo los llamaremos mediadores en la medida que sean capaces de transformar, traducir, distorsionar y modificar el significado o los elementos que se supone deben transportar:

No importa lo complicado que sea un intermediario, puede representar para todo propósito práctico, una unidad o incluso nada porque puede ser fácilmente olvidado. Por simple que pueda parecer un mediador, puede volverse complejo; puede llevar en múltiples direcciones que modificarán todas las descripciones contradictorias atribuidas a su rol (Latour, 2008: 63).

Para McLuhan, (1983) la tecnología de la imprenta creó el público, así como la tecnología eléctrica creó la masa; en esta categorización el público consistiría en individuos aislados que van de un lado a otro con puntos de vista separados, fijos. Con la nueva tecnología sobre nosotros, cabe abandonar el lujo de esta postura, este enfoque fragmentario, nos dice McLuhan. Es así que el entramado de mediadores virtuales no podría ser tratado únicamente como un medio de comunicación. Consiste y se manifiesta como una relación social plena, internacional, supraindividual y suprafuncional, con reciprocidad entre los sexos, generaciones y culturas, en la que se mezcla todo lo que constituye la vida social, a través del que se expresan las instituciones adoptando formas de interacción, prestación y distribución, a lo que se añaden a su vez fenómenos estéticos (Ángeles, 2010: 219).

Al momento no deja de ser celebrada una era enriquecida por las potencialidades de las redes digitales, bajo banderas como la Cibercultura, la inteligencia colectiva o la reorganización rizomática de la sociedad (Sibilia, 2008: 13). Encontramos hoy en día "realidades virtuales" o, si se quiere, "virtualidades reales" por todos lados: hay comunidades virtuales, universidades virtuales, política virtual y hasta sexo virtual, cambiando el modo en que experimentamos la realidad (Huber, 2002:16). Aquellos mediadores son capaces de transformar sin retorno la vida cotidiana en todos los niveles de observación del sistema social, es decir, desde las manifestaciones microestructurales hasta las nimias y fugitivas microescenas (Urresti, 2008). ¿El mensajero trastoca los mensajes? Vayamos directo al artefacto más inmediato, el celular.

Para Biondi y Zapata (2006: 51), por ejemplo no sólo las computadoras personales, sino los teléfonos celulares son parte del entramado mediador capaz de cambiar los 
mensajes: ciertamente aproximan a la gente, pero a la vez posibilitan el distanciamiento aun de aquellos que como el núcleo familiar permanecían antes próximos. Nada mejor que una caricatura, entre tantas, que circula en las redes sociales para asociar nuestras hipótesis a la realidad:

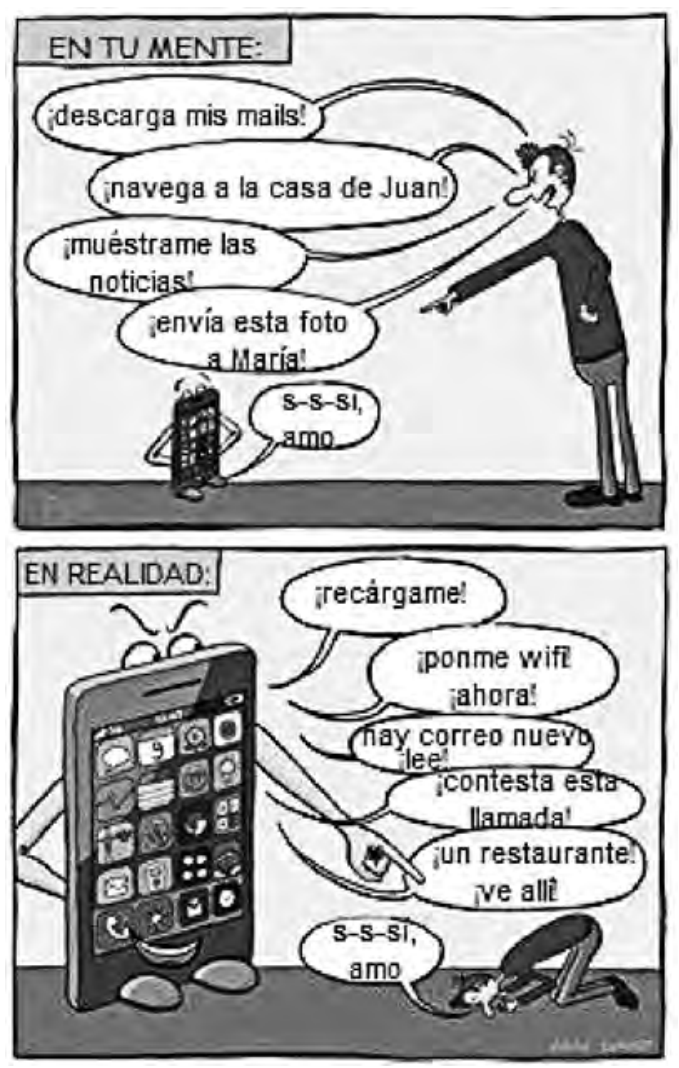

En la caricatura se aprecia una típica forma de transmitir mensajes en las redes sociales, en donde se contrasta la experiencia discursiva subjetiva con la realidad objetiva, considerada ésta última como verdad absoluta. Caricatura del mes de noviembre del 2014, en el grupo de Facebook Psicólogos Perú.

Los propios usuarios de las redes sociales proponen en esta imagen una serie de opiniones, en donde respaldarán aquella propuesta: somos esclavos del celular, es decir, somos prisioneros de aquellos artefactos que se suponen existen para servirnos. Más allá de sostener una dicotomía insalvable limitada a lo bueno o malo que puede ser el celular, veamos las opiniones más resaltantes en el Facebook a propósito de esta caricatura: 
Yoselin: Mmmmm creo que es la pura realidad, somos esclavos de unos dispositivos que aparentan ser tan, pero tan, insignificantes, pero en realidad nos ha robado el tiempo, la atención, y la convivencia muchas veces en familia sólo por los celulares.

Sheila: Totalmente cierto, podemos pensar por un momento que nosotros tenemos el control de la tecnología, sin darnos cuenta que en realidad es todo lo contrario. Buena imagen para reflexionar.

Vale: $\mathrm{Si}$, a veces... nos dejamos dominar por ese aparatito....y sí parecemos esclavos... no tiene que ser así... para todo hay tiempo...

Rosario: Las cosas nos poseen a nosotros.

Graciela: Lamentablemente sí, sobre todo con la mayoría de los jóvenes aunque no lo admitan. Hubo quienes escribieron sobre este fenómeno social hace alrededor de 35 años y la mayoría creyeron que era ficción...

Jesús: No estoy tan de acuerdo con esa realidad porque en mi caso y el de unos conocidos que tengo usamos el celular y sus bondades de la tecnología según nuestras necesidades, muy diferente a estudiantes en el que algunos (y no la mayoría) sí los noto pegados a sus juegos, Facebook, etc. como si fuera un vicio, pero no es como la realidad planteada en la imagen que sí me parece exagerada, es mi opinión por cierto.

Estas apreciaciones de jóvenes que no rebasan los 20 años de edad, podrían reflejar lo dicho por McLuhan (1985:190) hace un par de décadas: las nuevas tecnologías lo impulsan hacia una necesidad de interdependencia humana total. Rosario es enfática, las cosas nos poseen a nosotros. Para Jesús este tipo de animismo no nos lleva a ningún planteamiento serio ya que tanto él como sus amigos gozan del celular como una herramienta capaz de corresponder a la razón más utilitarista. Él mismo lo dice, algunos están "pegados" a sus juegos o al Facebook. Sin embargo dicha racionalidad, por más positiva que parezca, está alejada de ser cierta. En principio razón y emoción no son dos cualidades alejadas una de la otra, se corresponden al cuerpo mismo. No hay lugar para planteamientos binarios o polarizados. Además estas opiniones son parte de una reflexión que los arranca de su realidad más inmediata: el yo en su sentido más fenoménico, más íntimo y más personal. Opinan desde la exterioridad, analizando casos ajenos al propio. Se trata de una un análisis que deja entrever la sensación de que todo lo malo ocurre a las afueras de nuestro propio caso. Tomemos a continuación un diálogo que tiene a Pier como coprotagonista vía el chat del WhatsApp, al cual se accede desde el celular²:

10:51PM 20 de Sep - Pierrrrrrrrrr: Maniana puedes ???

10:51PM 20 de Sep - Claudia: No se

2 Diálogo sostenido en el año 2013 entre Pier de 20 años, estudiante de una universidad privada, perteneciente al distrito de Cercado de Lima; y Claudia de 21 años, estudiante de una universidad estatal, perteneciente al distrito de San Juan de Lurigancho. 
10:51PM 20 de Sep - Pierrrrrrrr: Dpend como avanse en la mañana cn lo q tngo q hacer $\mathrm{d}$ tareas

10:52PM 20 de Sep - Claudia: Por eso.

10:52PM 20 de Sep - Pierrrrrrr: Mmm..

10:52PM 20 de Sep - Pierrrrrrr: Ayia ok

10:52PM 20 de Sep - Pierrrrr: Entknces qe te tngo qr llamar cuando salga

10:52PM 20 de Sep - Pierrrrrr: Para qe me digas

10:53PM 20 de Sep - Claudia: Nop es necsario

10:53PM 20 de Sep - Claudia: Hablamos por aki

10:54PM 20 de Sep - Pierrrrr: Jajjaa :(

10:55PM 20 de Sep - Pierrrr: Pero tu no me respondes:(

10:55PM 20 de Sep - Claudia: Lo digo para q no t molests en llamar

10:55PM 20 de Sep - Claudia: Como normalment no hablamos mucho

10:55PM 20 de Sep - Claudia: Y mas por aca

10:56PM 20 de Sep - Claudia: Pero si me llamas esta bien :)

10:57PM 20 de Sep - Claudia: No mal interpretes las cosas ok

10:57PM 20 de Sep - Pierrrrrrr: Mmm...

10:57PM 20 de Sep - Pierrrrrr: Y yo porqe me molrsto ??

10:59PM 20 de Sep - Claudia: No es q lo digo porq normalmente hablamos por aca

10:59PM 20 de Sep - Pierrrrrr: Ayia pero

10:59PM 20 de Sep - Pierrrrrr: No se dime t

11:00PM 20 de Sep - Pierrrrrr:Yo te.llamo normal

11:00PM 20 de Sep - Pierrrrr: Pero cuando tu me llamas

11:00PM 20 de Sep - Pierrrrrr: Cuando dejo el.celu te.molestas

11:50PM 20 de Sep - Pierrrrrr: Ya te molestastes :(

Llamar o no llamar, escribir, timbrar, etc; son tantas las opciones que terminan por estresar la conciencia de Pier. Ello no es un fenómeno aislado, ya que dicho mediador móvil es capaz de provocar las más crudas peleas entre las parejas amorosas. La capacidad de los mediadores en ser actores, 0 , más precisamente, participantes en el curso de acción a la espera de que se les dé figuración, producto de lo cual las cosas pueden servir de telón de fondo, pudiendo autorizar, permitir, dar recursos, alentar, influir, bloquear, hacer posible, prohibir, etc. (Latour, 2008: 107). La reflexión de McLuhan (1983) nos llama una vez más a la reflexión, todos los medios son prolongaciones de alguna facultad humana, psíquica o física. Siendo el mundo del oído, un mundo de relaciones simultáneas (McLuhan, 1983), un mundo hiperestésico y caliente, a diferencia del mundo de la vista que es un mundo relativamente neutro y frío (McLuhan, 1985:29), analicemos, entonces, detenidamente el caso de ese "aparatito", el celular, desde sus propios jóvenes actores quienes, a la larga, tienen la última palabra en este intenso debate. 


\section{El celular y su ensamblaje con lo humano}

El teléfono celular representa hoy en día un elemento constitutivo del ser humano, inclusive de las personas que llegan a una avanzada edad. Son pocos aquellos que se resisten al uso del celular, acaso más por evitar ser dependientes de dicho artefacto, que por la incapacidad de saber utilizarlos. El celular es, además, una extensión de las tecnologías de las redes virtuales gracias a los aditivos provenientes del internet. Este instrumento viene jugando desde su aparición masiva a inicios de los años dos mil al día de hoy un papel preponderante en la socialización del individuo. Gracias a esta tecnología las juventudes, en busca de su emancipación, evitaron el molesto intermediario que representaba el teléfono fijo, dejando a un lado la amenaza que representaban los padres, hermanos; o de ser una familia extensiva, tíos, primos o abuelos, entre otros al poder contestar el teléfono. Además se podía ubicar a quien se quisiera en cualquier lado y a cualquier hora. De esta forma las juventudes se independizaron aún más, pudiendo tejer redes cada vez más amplias e itinerantes por un lado, así como superficiales y aparentes por otro.

Estamos frente a un fenómeno muy particular de redes sociales. Al abrirse al mundo desconocido de lo lúdico y lo erótico, el usuario en mención conocerá nuevos pares, con quienes intercambiará su número celular, y de quienes recibirá una serie de mensajes de texto ${ }^{3}$ para responderlos al instante de acuerdo al interés que posea. Éstos funcionaban con mucho arraigo como una variante del chat, es decir a modo de pequeñas notas reducidas que mantienen al usuario conectado constantemente a sus redes. Pero si bien los mensajes de texto cumplían ese rol, serán las redes sociales a través de la conexión a internet las que tomarán la batuta en esta función: Facebook, Twitter y WhatsApp, entre las más importantes, serán las que permitirían la mágica comunicación en tiempo real, intercambio de fotos y archivos en general, así como atisbar la vida privada de los demás con la entera complacencia de estos. Todo ello dejó de constituir una mera herramienta, llegando a ensamblarse al propio cuerpo humano, a sus emociones y sensibilidades más profundas. Se vivía el auge de los medios, que al modificar el ambiente, suscitarían en nosotros percepciones sensoriales de proporciones únicas. Una vez más la prolongación de cualquier sentido modificaría nuestra manera de pensar y de actuar, nuestra manera de percibir el mundo (McLuhan, 1983).

No es nada difícil de pensar el que los celulares hoy en día vienen ocupando un lugar privilegiado en la vida de los y las jóvenes. Y no es un secreto, ya que por doquier puede verse, leerse $u$ oírse que la dependencia hacia el celular, tanto en su función auditiva como escrita vía el chat, es eminente y masiva. Si tal como hemos analizado anteriormente, el

3 Me refiero a los mensajes que llegan al celular, los cuales no pueden poseer más de 160 palabras por mensaje, escritos desde algún celular o desde Internet. María Teresa Quiroz destaca cómo gracias a los mensajes de texto se producen transformaciones en el lenguaje. Las múltiples emociones que pueden expresarse a través del lenguaje en código amplían las fronteras de las comunicaciones interpersonales superando los constreñimientos del lenguaje escrito, estándar. No deja de ser sorprendente por ello, remarcando cómo la escritura ha penetrado en el territorio del teléfono celular, el instrumento oral por excelencia (Quiroz, 2008). 
celular no sólo trajo consigo la facilidad de la comunicación, sino que fue capaz de reacomodar nuestro comportamiento, nuestros hábitos e inclusive la corporeidad de nuestras emociones, cabe analizar el modo en que viene creando cierto ensamblaje ${ }^{4}$ entre lo humano y lo no humano. Sus usuarios ríen solos frente a la pantalla de sus Smartphones o de sus BlackBerrys ${ }^{5}$, caminan extraviados del mundo que los rodea sosteniendo entre sus manos la conexión al mundo virtual que sostiene sus experiencias de felicidad inmediata. Existen a través de las redes, a través de sus publicaciones y de las publicaciones ajenas. Incorporan en sí la compleja tecnología que día a día se acomoda a las necesidades de sus exigentes consumidores.

Analicemos el testimonio de Valerio, quien durante su vida ha venido construyendo, más que una dependencia, un ensamblaje con aquel mediador. A través de él podía existir en la conexión con el cuerpo social que ya estaba siendo conectado a una realidad virtual de pares:

Al pasar los años veía los nuevos modelos de celulares, con cámara, reproductor de audio, de video y lo último de lo último el infra rojo, este servía para pasar información de celular en celular siempre y cuando lo tengas juntos bien juntos. Y en verdad me moría por uno de ellos. Les dije a mis padres que me compraran uno y siempre decían no, estás muy mocoso para que tengas eso, es que mis padres no nacieron con la tecnología, pero yo sí y necesitaba uno de esos teléfonos, además no creo que sea un mocoso, tenía 14 años y mi salvación para estar conectados con los demás, es decir amigos y conocidos, era por medio del chat vía internet. ${ }^{6}$

Las generaciones que anteceden a las juventudes que han visto pasar sus años de esfuerzos por socializarse con sus pares, son incapaces de identificar la importancia que puede tener aquel artefacto en sus vidas. A sus 14 años Valerio se veía a sí mismo como alguien incompleto, como si una parte de su cuerpo hubiera sido amputada, a pesar de que nunca fue parte de él. Podemos ver por doquier cómo es que el celular no se separa del usuario ni siquiera en las necesidades más privadas, siendo un constante conector a la gran red masiva a la cual pertenece. Más aun esto se ha multiplicado gracias al acceso al internet móvil, función no sólo popular entre jóvenes y adultos, sino casi inevitable al momento de portar un celular. Aunque se presumía en un inicio que este mediador servía como elemento de distinción de los unos sobre los otros, gracias a sus diversos usos, tales como cámara, radio, MP3 entre otros, buscando sentirse más que los demás a través de dicho capital simbólico.

Si en un inicio parecía ser un objeto de distinción, hoy su principal característica radica en haber mutado en un fin en sí mismo: basta constatar cómo los celulares cuyos

4 Mi agradecimiento a Guillermo Nugent por la sugerencia de esta categoría en el análisis de mis datos.

5 Para fines del año 2014 el Blackberry había desaparecido, casi en su totalidad, de las manos juveniles que se habían entregado a la magia virtual del Smartphone.

6 Entrevista a Valerio del año 2014. Tiene 20 años y estudia en una universidad privada. Vive en Santa Anita. 
modelos poseen las funciones más modernas, se han generalizado en el público juvenil de Lima —incluyendo al público infantil— dejando a un lado las diferenciaciones, aunándolos bajo el techo de la modernidad y la tecnología. Sólo así se explica la existencia de modelos modernos y de precios altos, en manos de jóvenes pertenecientes a estratos medios y bajos: el celular deja de ser un elemento de tercer orden para ser un objeto de vital importancia, como signo de poder comunicativo, moderno y a la vez emotivo, en la relación sujeto-tecnología. Basta citar tantas frases en conversaciones cotidianas, en publicaciones en el Facebook, todo ello se puede resumir en lo que diría cierta joven: " Buuuu Se me murió el celular, es el peor día de mi vida!".

Lo irónico de los celulares radica en que si bien conectan a unos y otros, lo hacen a la distancia, ampliando dicho trecho en una especie suplantación de la relación cara a cara por una mediante dicho artefacto: los celulares permitirían a los que se conectan mantenerse a distancia (Bauman, 2007: 85). Nos dice Bauman:

Comunicarse por e-mail y hablar por teléfono celular tienen la misma función manifiesta (establecer contacto), pero también muy diferentes funciones latentes. La función latente de los celulares, que al e-mail le falta irremediablemente, es que le permiten a quien habla desentenderse del lugar en el que están corporalmente sumergidos en ese momento: estar en otro lado, ser "extraterritoriales", libres de las ataduras del espacio físico que sus cuerpos ocupan sin embargo, también les ofrecen a quienes hablan la facilidad de manifestar y hacer de conocimiento público su descompromiso, donde y cuando les es más necesario hacerlo (Bauman, 2004: 190).

Tentación electrónica que declara su propiedad sobre la libertad humana: una vez que usted tiene su celular, ya nunca está afuera. Uno siempre está adentro, pero jamás encerrado en ningún lugar (Bauman, 2007: 84). Tenemos así, una gama muy compleja de tecnologías que podrían establecerse en dos modalidades: de un lado el teléfono móvil como nexo de libertad de conexión alguna con la esfera parental, y por otro como microuniverso autónomo, de apertura al mundo e identificación; y ambos relacionados como "medios amigos" de interacción e integración permanente con los pares (Ángeles, 2010: 206).

En palabras de McLuhan asimilamos el contenido de un texto por medio de una especie de masticación quele saca todo su sabor (...) gustarlo con palatum cordis o en ore cordis. Toda esta actividad es, necesariamente, una oración: la lectio divina es una lectura piadosa (...) cuando se lee, déjalo buscar el sabor, no la ciencia. (McLuhan, 1985: 113). Pero no limitemos esta tecnología a la oralidad de nuestros oídos, ya que el resto de nuestras extremidades también participan, como es el caso de nuestras manos. En el caso de la función del chat o mensajería instantánea, los dedos pasan a ser complementos de nuestro artefacto, llevándonos a escribir durante todo el día una serie de mensajes vía el chat del WattsApp o acaso vía el chat del Facebook, inclusive a través de tweets. 
Las críticas del maestro lingüista Antonio Cisneros resuenan muy inquisitivamente: Si la escritura nos permite adquirir una dimensión diacrónica de la cultura y transitar por sus espacios temporales, los mensajes electrónicos nos insertan en un aquíy un ahora inmediatos, sin tiempo para recorrery auscultar sus antecedentes y sin preocupación alguna por su porvenir (Cisneros, 2006: 24). Nadie discute el carácter oral con que adviene esta cultura electrónica, sin embargo analicemos más fondo cómo es que se desarrolla. Sí, en efecto, con el advenimiento del internet la comunicación vía chat se hizo sumamente fluida, dejando en un segundo plano por momentos, inclusive, la comunicación sonora de la telefonía celular.

Y es que, como establece Cisneros (2006: 24), aquella oralidad ni siquiera se servirá de las palabras, sino de las imágenes, las cuales simbolizarán en un modo mucho más complejo y sugestivo lo que los usuarios desean transmitir. Con ello nos referimos a las fotografías, a los íconos, a los guiños virtuales, iconos sonrientes o tristes, envío de besos, entre otras maromas iconófilas de un mundo que cada vez deja a un lado las composiciones más complejas para adecuar la comunicación en textos breves, concisos, y a la larga, de una oralidad indiscutible. Es así como el fluir acústico del lenguaje (aparentemente sólo escrito) es ingeniosamente elaborado a fin de mantener atento el oído mediante el eco fue reordenado con arreglo a unas estructuras visuales creadas por la esmerada atención del ojo (Havelock, 1996: 33). Esto es lo que llamaremos la intrusión de la oralidad en la escribalidad. Analicemos esto.

\section{Oralidad y electronalidad en la interacción tecnológica juvenil}

Hemos discutido brevemente cómo es que el celular ocupa un lugar privilegiado en nuestras vidas, o más específicamente en nuestros cuerpos. A partir de la propuesta de los medios como mensajes, McLuhan argumentó que la tecnología electrónica, tan acendradamente acústica, reintrodujo una forma de comunicación y de experiencia no lineal y más rica, resucitando formas que habían existido, según insinuaba, antes de que la comunicación humana se amorteciera a manos de la imprenta (Cit. en Havelock, 1996; 50). Para McLuhan, acentuar únicamente el componente visual a través de la escritura, nos obligó a olvidar la oralidad de antaño, creando en nosotros mismos esa enorme área de ridículo y estupidez (McLuhan, 1985:289), que supuso, en sus inicios, a tildar de depravada toda área relacionada a los medios de comunicación, por representar para ellos una actividad típicamente oral. Acudíamos al forzado desencantamiento del mundo a partir del uso racional de las tecnologías.

Los jóvenes, una vez más, serían los potentes usuarios de aquella oralidad inicial en los medios de comunicación detentada por la radio y la televisión. La cultura de la masa, sería resultado de aquellos mediadores eléctricos que nos habrían devuelto la utilidad de aquellos otros sentidos enterrados en el olvido: en la separación misma de la facultad visual y el resto de los sentidos en su interacción, condujo al rechazo por la conciencia de gran parte 
de nuestra experiencia y a la consecuente hipertrofia del inconsciente (McLuhan, 1985:301). McLuhan habría estado convencido de aquella dicotomía oralidad-escritura, Ilevándolo incluso a una perspectiva que ponga en tela de juicio el propio conocimiento científico:

¿Si podemos discurrir un medio conveniente para traducir todos los aspectos de nuestro mundo al lenguaje de un sentido solamente, tendremos entonces una distorsión que será científica, porque es consecuente y coherente? (...) El predominio de uno de los sentidos es la fórmula de la hipnosis. Y una cultura puede ser encerrada en el sueño de cualquiera de los sentidos. El durmiente despierta cuando es requerido por cualquier otro sentido (McLuhan, 1985: 94).

¿Acaso no hay una superior elaboración de la conciencia humana a través de los sentidos que se desprenden de la vista? ¿Acaso habríamos rehuido durante muchos años de las bondades del oído? ¿Hoy en día estaríamos retomándolo gracias a una electronalidad tan sugestiva como seductora? Lo cierto es que dicho optimismo no habría tenido la suficiente resonancia en la desconfianza que muchos abrigan debido al regreso de la oralidad, convirtiéndose en un peligro capaz de atentar contra la razón más fecunda:

Lo trascendente se ha convertido en solo lo puntual. Verdad es que la palabra vuela, pero ocurre que esta palabra es recibida ahora simultáneamente por la multitud y surte efecto inmediato en una vasta audiencia de indiscriminada (e indiscriminable) capacidad de discernimiento. La cultura (....) resulta ser a veces una comunicación eventual y entrecortada (Cisneros, 2005:25).

Para ejemplificar este punto, al referirse a la televisión, Sartori (1998) denunció la pérdida de la capacidad de abstracción que estaba provocando la exposición de los niños a las imágenes en la pantalla televisiva. Para este autor se va creando un ser video-dependiente que se traga las imágenes sin masticar, saltándose el proceso de la razón y la crítica. El niño perdería así, concluye Sartori, la visión que le ofrece la lectura de la palabra escrita sumergiéndose en un mar de complacencia sin aplicar el más mínimo sentido crítico ${ }^{7}$. Asimismo Benjamin da cuenta del modo en que las secuelas de la tecnificación habían desatado ya, por la década de los treinta, tensiones que rayaban en lo psicótico. Aunque nos proponía un análisis pormenorizado del cine de aquella época, que empezaba a generar gustos repetitivos en masas cada vez mayores, podemos servirnos de dicho planteamiento:

7 Incluso hay quienes son aún más críticos al referirse a los medios de comunicación como modos de opresión cultural: Del mismo modo que debemos saber que ciertos productos son comida chatarra, que no alimenta y que debemos evitar ser parte de la civilización del desecho, que nos está inundando de basura, es importante reconocer que buena parte de lo que se da en la escuela o en Internet no es sino basura: no tiene sentido adquirirla y mucho menos conservarla (Esteva, 2011: 172). 
Se llega al reconocimiento de que esta misma tecnificación ha creado la posibilidad de una vacuna psíquica contra tales psicosis masivas mediante (...) un desarrollo forzado de fantasías sádicas o alucinaciones masoquistas es capaz de impedir su natural maduración peligrosa entre las masas. La carcajada colectiva representa un estallido anticipado y bienhechor de psicosis colectivas de este tipo. Las colosales cantidades de sucesos grotescos que se consumen (...) son un agudo indicio de los peligros que amenazan a la humanidad (Benjamin, 2003: 88).

Benjamin decía esto poco antes del estallido de la segunda guerra mundial. Sin embargo este análisis ha perdido un elemento importante. En la actualidad no son las masas las que siguen enunciados comunes, puesto que a nuestro entender, los usuarios de la comunicación son tan individualistas que se sirven de sí mismos para hallar el placer en una tecnificación autárquica. Sus carcajadas son vividas al unísono pero a una considerable distancia física, gracias a la ilusión de estar muy cerca a través de la tecnología, que resulta cada vez más audaz, cada vez más engañosa. La comunicación oral se apodera de la interacción socializadora más básica con estrategias tan placenteras como seductoras. Si bien el mundo va reencantándose, ya que se convive con cierta magia tribal, el aislamiento individualista crece de la mano con el convencimiento de estar juntos los unos y los otros.

Es así que, como establecimos líneas atrás, la comunicación vía chat (ya sea desde la computadora, lap top, tablet, o smartphone) al ser "entrecortada", es decir tan básica como puntual, disminuye la capacidad de "discernimiento", algo así como que se escribe pensando, un rasgo típicamente oral en que se habla lo que se piensa. Para comunicarnos en el mundo de la escribalidad se debe reflexionar lo suficiente para amalgamar pensamientos e ideas: salir de sí pensando mínimamente lo que se ha de construir.

Sin embargo McLuhan había rechazado estas ideas años atrás, sosteniendo que no se puede sobrevivir si uno enfoca su ambiente, el drama social, desde un punto de vista fijo, inmutable (como lo puede ser la vista a través de la escritura): la estúpida respuesta reiterativa ante lo que no se percibe (McLuhan, 1983). Irónicamente nos dice que ahora todo el mundo es un sabio (McLuhan, 1983) en respuesta a la limitada visión de la propia vista que se siente empoderada de todo conocimiento digno de ser considerado como único, alejado de la atrasada oralidad. Su propuesta es tan convincente como atrevida:

El predominio de lo visual, en detrimento de los otros sentidos, creó por doquier unidades homologadas, un universo lineal y desmenuzado, encapsulado en categorías analíticas, unilateral. El sentido visual extendido a partir del alfabetismo fonético (creó) la costumbre analítica de captar un solo aspecto de la vida de las formas (McLuhan, 1985: V).

Sin embargo nos preguntamos, retomando una idea suelta que propusimos al final del acápite anterior, ¿es la comunicación oral el instrumento de una mentalidad oral, de un tipo de conciencia notablemente diferente de la mentalidad alfabetizada? (Havelock, 1996: 47). 
Antes que una disociación, creemos que la oralidad habría encontrado cierto lugar en el desarrollo tecnológico eléctrico en los últimos cincuenta años sin suprimir la escritura como despliegue de un conocimiento cultural, capaz de convivir con el resto de sentidos. La ecuación oralidad-escritura no es acorde a lo que se viene experimentando. Se trataría de unas segundas nupcias de los recursos de la palabra escrita y la hablada, matrimonio que reforzó las energías latentes de ambas partes (...) la tecnología que ha reavivado el uso del oído ha reforzado, al mismo tiempo, el poder del ojo y de la palabra escrita que es vista y leída (Havelock, 1996: 58).

Para analizar lo que ha venido ocurriendo en los últimos años podemos partir del Messenger como emancipador de las relaciones cara a cara, el cual fue capaz de animar a sus usuarios y usuarias a renovar los lenguajes, comportamientos y valores sociales juveniles durante los años que mantuvo su hegemonía ${ }^{8}$. El Messenger rebasó los límites concebidos hasta aquel momento, gracias a que el lenguaje le permitiría a la inteligencia, pasar de un punto a otro con mayor facilidad y rapidez y con una implicación cada vez menor (McLuhan 1996: 97), es decir, aludía a recursos orales en donde se puede ir de un contexto a otro sin mayor remordimiento. A medida que los años han pasado, una serie de formas y representaciones lingüísticas se han venido desarrollando, creando códigos y dialectos totalmente independientes de las reglas lingüísticas más básicas, en una sintonía acorde a la jerga, suspende giros y efectos, anula consecuencias y trayectos, renueva posturas e imposturas (Hevia 2008: 19).

¿La escritura se sirve de la oralidad? ¿O es que acaso la oralidad se sirve de la escritura para potenciar aún más aquel sentimiento presenteísta del acontecimiento inmediato? Pareciera que la musa de la oralidad, cantora, recitadora y memorizadora, está aprendiendo a leer y escribir; pero al mismo tiempo continúa también cantando (Havelock, 1996: 45). La oralidad nos golpea con la fuerza de la verdad y de la historia, admite Cisneros (2006), es capaz de removernos, y al penetrarnos, nos convoca a la hora inicial de la lengua. La escribalidad, en cambio, nos obliga a descifrar y nos propone una representación de equilibrado cálculo (Cisneros, 2006:26). ¿Quién quiere detenerse a tales esfuerzos en contextos en los cuales hasta memorias externas de numerosos gigabytes y terabytes se venden por doquier? Si ni siquiera queremos recordar las mínimas cosas, ¿cómo se puede suponer que desearemos desaprovechar las bondades de la oralidad?

Para rastrear las formas de oralidad en los últimos años, tomemos como ejemplo a los nicknames que existieron durante la época en que el Messenger monopolizó la comunicación en tiempo real (más conocida como chat). Éstos son los nombres con los que se presentan los usuarios ante el resto, es lo que antecede a lo que se dirá a continuación. Sin embargo eran pocos los que colocaban un nombre o un simple sobrenombre. Los nicknames o nicks publicaban diversos mensajes, los que podían ser visualizados por todos los "contactos" del usuario.

8 Nos referimos al periodo aproximado 2004-2011, ya para el año 2013 éste desapareció por completo fusionándose al Skype, otro modo de chat que incluye entre sus bondades la comunicación a través de videoconferencias. 
Hoy en día ello ha sido exportado hacia el Facebook de un modo más complejo: una cotidianidad expuesta a todo el público a través de los "estados", es decir del modo en que uno se siente emocionalmente o en que se declaran las actividades que se vienen ejerciendo. Es una simbología que permite al resto saber qué dice el otro, pero sin decirlo. Los amigos y amigas la respaldarán estructurando aún más este discurso a través de comentarios diversos, en su mayoría acompañadas de imágenes. De este modo el lenguaje hace posible, con los medios "adquiridos", un discurso distinto, permite un uso inhabitual de lo habitual, saca a la luz la originalidad en lo que, aparente y realmente, arrastra por doquier, que en su prostitución universal puede siempre encontrar una virginidad intacta (Castoriadis, 1989: 90).

Para la lingüista Caravedo quizás lo interesante del propio lenguaje reside en dar el salto de las normas ideales, ajenas o desajustadas, a las normas realmente aceptadas o, por lo menos, reconocidas como propias de la comunidad (Caravedo, 1989:12). Partiendo de dicha premisa, encontramos en todas las construcciones escritas con inspiración oral una serie de informalidades que definen estilos etarios y estratificados. La virtualidad se servirá de todos los sentidos, y no se limitará en la búsqueda del placer de sus consumidores.

Será capaz de transformar las propias cimientes de la comunicación más convencional, estallando en una anarquía compartida por una generación desinteresada en lo que opinen los otros. La oralidad se hace patente aun con mayor fuerza hoy en día: La musa cantora se trasmuta en escritora: ella que requería a los hombres que la escucharan los invita ahora a leer. Es justo asignarle ambos papeles. ¿No se inventó el alfabeto bajo su égida, cuando su canto aún imperaba? ¿Acaso hemos de negarle el mérito del invento y "de saberlo usar ella misma"? (Havelock, 1996: 94).

Contra todo supuesto por las instituciones educativas o por los dogmas academicistas más puristas, la electrónica ha propiciado procesos de re oralización de sociedades escribales, lógicamente sin que esto signifique la desaparición de la palabra escrita (Biondi y Zapata, 2006:61). La oralidad se adueña de las redes sociales menospreciando la lentitud y premiando la velocidad. Para Cisneros esto no tendría nada positivo:

Esta irrupción tecnológica, y su incontenible avance, y su demencial imperio, han terminado por conmover los valores que creíamos más estables, han generado una acongojante desazón espiritual, han maltratado la precaria fe que alimentaba nuestra condición humana, han confundido los límites de la inteligencia y han propiciado que mucha gente transitara naturalmente de la oralidad hacia la electrónica, sin pasar conscientemente por la escritura (Cisneros, 2005: 24).

Acudiríamos a los bordes de la reflexión, que en el sentido oral cobra formas simultáneas a diferencia de la escritura que limitaba nuestros sentidos a la visualidad. Según sostiene Mc Luhan lo visual es lo explícito, lo uniforme, lo secuencial (...) los modos analfabetos son implícitos, simultáneos y discontinuos sea en el pasado primitivo o en el presente electrónico (McLuhan, 1985:75). Veamos el siguiente testimonio anónimo en donde se puede analizar 
cómo es que piensa escribiendo, es decir se actúa oralmente sin que el usuario se detenga un momento a reflexionar sobre lo que escribe con lo cual la oralidad ingresaría triunfal por las puertas de las innovaciones tecnológicas, por las puertas de la virtualidad:

Normalmente escribo lo primero que pienso y varias veces me meto en problemas ante ello pero como conozco a la persona con la que estoy hablando y tengo una base sólida de amistad y confianza, puedo bromearle con respecto a una chica de mi carrera que le gusta, por eso en cada pequeña oportunidad que tengo de molestarlo, lo hago?

\section{Inmediatez e irracionalidad virtual}

Es inevitable negarlo mediante una serie de sermones o de huidizas y circunstanciales maniobras conservadas para evitarlo: las consecuencias de la oralidad en lo electrónico nos lleva a una inmediatez espacial y temporal, un aquí y ahora, aun cuando se hable del pasado, se suele emplear el presente histórico (Biondi y Zapata, 2006:60). En el juego identitario del Internet, el "otro" (destinatario y remitente de mensajes) queda reducido a su núcleo duro de instrumentos manipulables para la reconfirmación personal, despojado de todos o casi todos los rasgos irrelevantes para la tarea que todavía se toleran en una interacción off line (Bauman, 2007: 157). Se reduce al Otro hasta convertirle en lo único que realmente importa: instrumento de la propia autoconfirmación.

No hay modo de reflexionar sobre aquello que se piensa instantáneamente, son formas simultáneas que escapan a las explicaciones, porque difícilmente dejan rastro. ¿Qué es, a fin de cuentas, la oralidad si no la actuación de la boca de una persona que se dirige al oído de otra persona y escucha con su propio oído personal la respuesta personal espontánea? (Havelock, 1996:96). La oralidad se apoderó de las redes sociales, sin desvincularse de la vista, aunque rebajándola la mayoría de las veces. Para McLuhan (1985:42) como la electricidad crea unas condiciones de extrema interdependencia a escala global nos movemos velozmente hacia un mundo auditivo de sucesos simultáneos y conocido de extremo a extremo.

En este punto propondremos una hipótesis que nos llama al análisis de dichas comunicaciones: La oralidad a la que nos referimos no sólo se explicaría desde simbolismos e imágenes, sino a partir del aquí y el ahora. La oralidad expresada en las redes virtuales publica al mismo tiempo lo que se piensa. No hay una secuencialidad de pensar y escribir. Es escribir pensando, o mejor dicho, publicar pensando. La oralidad es acción y no mero ideal o principio. En palabras de Havelock (1996:109-110) la acción requiere a su vez unos agentes que estén haciendo algo o diciendo algo acerca de lo que están haciendo, o a quienes se les esté haciendo algo. Parece que un lenguaje de la acción, no de la reflexión, es requisito previo de la memorización oral. Después de todo, las formas tecnológicas de

9 Testimonio recogido en el año 2014, en un joven usuario de 18 años del distrito de Chorrillos, estudiante de Arquitectura de una universidad privada. 
vida son demasiado rápidas para la reflexión y demasiado veloces para la linealidad. En las redes sociales podrán leerse reflexiones en "voz alta", pensadas al mismo momento en que se publicaron. Aparentemente no dejarían rastros, aunque ciertamente lo hacen. Esa oralidad no es tan oral como creemos y es capaz de producirnos problemas personales y laborales, tal vez no al día siguiente, pero sí en algún momento de nuestras vidas, ya que podrían quedar absorbidas en la memoria externa de algún curioso consumidor que desee utilizarlo contra nosotros.

No se está al servicio de los demás, sino de uno mismo: se publica pensando, se existe publicando. Otorga el poder de aislarse, es un estar con los demás sin estar con los demás. Una oralidad engañosa y quisquillosa. La musa de la oralidad que aprendió a escribir, también aprende a engañar. Para McLuhan, si bien la imprenta hiptonizó al mundo occidental mucho tiempo atrás, el hechizo del sentido visual ya no es más lo que fue con el advenimiento de la electricidad ¿estamos acaso bajo los efectos de un nuevo hechizo? ¿Sería mejor hablar de supuestos o parámetros o estructuras de referencia como él señala?:

No importa cuál sea la metáfora, ¿no es absurdo que los hombres vivan involuntariamente alterados en su vida interior por alguna simple extensión tecnológica de sus sentidos íntimos? el cambio de proporción entre nuestros sentidos provocado por la exteriorización de ellos, no es una situación ante la que hayamos de sentirnos impotentes. Los computadores pueden ser programados ahora para toda posible variedad de proporciones de los sentidos (McLuhan, 1985:217).

Mc Luhan no pudo ver los límites de su propuesta, ya que estos tiempos son mucho más de lo que la ficción pudo prever. Los mediadores han trasformado nuestra realidad social a través de la era de la información, a través de la globalización. La oralidad cunde en las redes virtuales, y nuestro entorno amical exige ver nuevas publicaciones al mismo modo que nosotros debemos continuar publicando. Ello nos recuerda lo que Elías sostenía como fantasías colectivas:

Existe una amalgama de observaciones realistas y fantasías colectivas, en donde una imagen realista expresada en público puede debilitar la cohesión y el Sentimiento de solidaridad del grupo, y, con éstos, su capacidad de supervivencia. De hecho, en todos estos grupos existe un grado de distanciamiento que ninguno de sus miembros puede sobrepasar sin aparecer a los ojos del grupo como hereje (y convertirse en tal), sin importar que sus ideas o teorías concuerden con los hechos observables y se acerquen a aquello que llamamos "verdad" (Elías, 2002: 43).

Poner en tela de juicio todo eso que sostiene la sociabilidad virtual sería corromper la racionalidad que ha venido construyéndose desde hace unos años. La oralidad traiciona nuestras propias formas de comportarnos. Arranca modos informales que se perennizan 
en la web, de la cual muchos terminan aprovechándose. Parecerían meras expresiones inofensivas en complicidad con la virtualidad oral, que si bien aparenta esconderlo todo, a la larga lo publica todo. Entiéndase que si bien cada sujeto piensa y escribe aquello que desea en la soledad, por ejemplo, de su cuarto, seguirá formando parte de una relación social en la que uno se dirige a otras personas y, al mismo tiempo, a la propia persona (Mead, 1990: 173). Atentar contra todas estas fantasías colectivas sirviéndose de las razones más cuerdas y objetivas, de poco o nada vale. Habrá que rescatar el valor de la expresión "sentido común". No es, como alguien podría suponer, conocimiento ligero. Es consecuencia y expresión de un sentido compartido. Arraigado en largas prácticas de argumentación oral practicadas por las sociedades en el manejo mismo de la lengua (Biondi y Zapata, 2006: 49).

\section{Conclusiones}

McLuhan creía que la nueva oralidad uniría a todo el planeta del mismo modo en que la oralidad acerca a las comunidades pre modernas. Creía que seríamos una especie de aldea en donde todos estaríamos tan cerca y que, gracias a lo cual, podríamos entendernos mejor, comprendernos y hasta crear lazos de solidaridad capaces de construir una sociedad colectiva que rebase el mundo individualizado de la escribalidad, que se caracteriza por albergar actores que perciben lo que les rodea a su antojo, únicamente a través de sus propios ojos, de modo egoísta y escindido de la comunidad. El oído, en cambio, sería capaz de acercarnos a todos, recreando una aldea a escala global. Fue así que McLuhan instituiría una frase conocida por todos aun al día de hoy: la aldea global. Sin embargo pareciera frustrante comprobar que dicha hipótesis, o más aun, dicha profecía, no fue tan cierta ya que los medios sobrepasan a sus hacedores.

La tecnología con la que nos comunicamos son mediadores capaces de malversar o malinterpretar nuestros mensajes, insertando un significado que nosotros mismos terminamos por aceptar, limitándonos a su lógica, a su modo oralizado de ver el mundo. Es así como los mensajes enviados o recibidos trascienden la lógica de la simple tergiversación, cobrando un significado nuevo que se entremezcla con los deseos del usuario, incrementando su riqueza significativa, sin dejar de limitarlo a los mecanismos tecnológicos de la nueva oralidad.

La complejidad de la vida cotidiana se refleja en frases reducidas y sin mayor riqueza interpretativa o argumentativa, imposibilitando la redacción de ideas concatenadas mucho más complejas, sintetizando las sensibilidades y emociones, así como el análisis y la reflexión, a un"aquí y ahora" vago e inconstante. Se vive el ahora y el presente como única fuente vital de existencia, incrementando la necesidad de un "beatus ile" y un "memento vivere", que angustia aun más a sus usuarios ante el transcurrir inmediato del presente. Los desgasta y agota, puesto que deben encontrar nuevas formas de sentir y degustar la 
vida totalmente nuevas y diferentes. Colores y sonidos se multiplican ante la necesidad de incrementar nuevas formas de distracción psíquica y mental.

La oralidad es patrimonio vivo de muchos pueblos y naciones que conviven con occidente, incluidos en el Perú, lo cual los lleva a solidarias formas de convivir y existir. Pero esta oralidad es extraordinariamente distante de la electronalidad que consumimos. Vivimos en un mundo interactivo que va alejando cada vez más a sus usuarios, en donde la socialización como base de la convivencia se ve afectada. Los no lugares, comprendidos como espacios de una narcisista existencia en que no necesitamos del resto, en donde no nos importa los demás, parecieran ser el nuevo contexto global que va significando la nueva socialización entre los y las jóvenes. ¿Cómo sería esto posible si nos interesamos tanto en el espectáculo de la privacidad de amigos y amigas, es decir del otro generalizado? ¿Si nos esforzamos en decir al otro generalizado lo que hacemos y sentimos cada minuto? ¿Si chateamos horas de horas con docenas de amigos y amigas a la vez? Si hoy más que nunca estamos en constante interacción con todos y todas, ¿Es que acaso McLuhan tenía razón?

Si bien cada acción emprendida a partir de la utilización de los mediadores nos hace creer que estos sirven a nuestras metas más racionales, terminamos por conjurar, de modo sincrético con la máquina, formas de apartarnos de los demás, acudiendo a ellos mediante otros caminos. Ello si bien aleja únicamente los cuerpos, no alejará las emociones que se mantienen en contacto virtual, éstas cambian y se transforman ante la supuesta creencia de tener muy cerca a aquella persona o personas, al punto de prescindir de las mismas. Dependencia, burla, jocosidad y hedonismo se vuelven cada vez más parte de nuestro mundo, aquel que convive con las fantasías individuales de los actores sociales. A fin de cuentas todo cabe en un pequeño aparatito, todo cabe en nuestras manos, volviéndonos tan autosuficientes, descuidando el modo que vamos horadando más y más en nuestra más compleja soledad.

\section{Referencias bibliográficas}

ÁNGELES, Gil (2010) "Generación digital: patrones de consumo de Internet, cultura juvenil y cambio social" En Revista de Estudios de Juventud Nº 88 http://www.injuve.es/

ARRIAGA, Rafael. (2014).“De MaxWeber a Michel Maffesoli: inmigración, reencantamiento del mundo y politeísmo de valores en Estados Unidos". En Época II. Vol. II № 2. pp. 179-209.

BAUMAN, Zygmunt (2004) La sociedad sitiada. Buenos Aires, Fondo de cultura económica.

BAUMAN, Zygmunt (2007) Vida de consumo. México D.F.: Fondo de cultura económica.

BENJAMIN, Walter (2003) La obra de arte en la época de su reproductibilidad técnica. México D.F.: Editorial Ítaca.

BIONDI, Juan y ZAPATA, Eduardo (2006) La palabra permanente. Lima: Fondo Editorial del Congreso. CARAVEDO, Rocío (1989) El español de Lima. Lima: Fondo Editorial PUCP.

CASTORIADIS, Cornelius (1989) La institución imaginaria de la sociedad, t. II. Barcelona:Tuquets Editores. 
Cisneros, Luis (2006) Prólogo. En Juan Biondi y Eduardo Zapata. La palabra permanente. Lima: Fondo Editorial del Congreso. pp. 23-34.

ELÍAS, Norbet (2002) Compromiso y distanciamiento. Barcelona: Ediciones Península.

ESTEVA, Gustavo. (2011)“Más allá de la educación". En L. Meyer y B. Maldonado. Coord. Comunalidad, educación y resistencia indígena en la era global. Oaxaca: CSEIIO. pp. 159-174.

HAVELOCK, Eric (1996) La musa aprende a escribir. Barcelona: Paidós.

HUBER, Ludwig (2002) Consumo, cultura e identidad en el mundo globalizado. Lima: IEP.

QUIROZ, María Teresa (2008) "Jóvenes e relaciones interactivas". IX Asociación Latinoamericana de Investigación de la Comunicación. En http://www.alaic.net/alaic30/ponencias/cartas/ COMUNICACION_Y_EDUCACIO/ponencias/GT6-10QUIROZ.pdf

LATOUR, Bruno (2008) Reensamblar lo social. Buenos Aires: Manantial.

MAFFESOLI, Michel (1993) El conocimiento ordinario. Compendio de Sociología. México D.F.: Fondo de Cultura Económica.

MCLUHAN, Marshall (1985) La galaxia de Gutenberg. Barcelona: Planeta.

MCLUHAN, Marshall (1996) Comprender los medios de comunicación. Las extensiones del ser Humano. Buenos Aires: Paidós.

MCLUHAN, Marshall y FIORE, Quentin (1983) El medio es el masaje. Barcelona: Paidós.

MEAD, G.H. (1990) Espíritu, persona y sociedad. México D.F.: Paidós Studio.

RIBEYRO, Julio Ramón (1986) Cuentos populares. Lima: Munilibros 2.

RORTY, Richard (1991) Contingencia, ironía y solidaridad. Barcelona: Paidós.

SARTORI, Giovanni (1998) Homo Videns. La sociedad teledirigida. Buenos Aires: Taurus.

SIBILIA, Paula (2008) La intimidad como espectáculo. Buenos Aires: Fondo de Cultura Económica. URRESTI, Marcelo (2008): "Ciberculturas juveniles:Vida cotidiana, subjetividad y pertenencia entre los jóvenes ante el impacto de las nuevas tecnologías de la comunicación y la información". En Ciberculturas Juveniles. Marcelo Urresti (editor), Buenos Aires: La Crujía ediciones. 